\title{
DISASTER CONSEQUENCE MITIGATION AND EVALUATION OF ROADSIDE GREEN SPACES IN NANJING
}

\author{
Wenjun FEI ${ }^{1^{*}}$, Zhijia JIN ${ }^{1}$, Jienan $\mathrm{YE}^{2}$, Prasanna DIVIGALPITIYA ${ }^{3}$, Takeru SAKAI ${ }^{4}$, \\ Chengkang WANG ${ }^{1}$ \\ ${ }^{1}$ College of Landscape Architecture, Nanjing Forestry University, No. 159, Longpan Road, \\ Nanjing, Jiangsu, China \\ ${ }^{2}$ College of Art \& Design, Nanjing Forestry University, No. 159, Longpan Road, Nanjing, Jiangsu, China \\ ${ }^{3}$ Faculty of Human-Environment Studies, Kyushu University, 744 Motooka Nishi-ku, Fukuoka 819-0395, Japan \\ ${ }^{4}$ Campus Planning Office, Kyushu University, 744 Motooka Nishi-ku, Fukuoka 819-0395, Japan
}

Received 24 June 2018; accepted 22 November 2018

\begin{abstract}
The extensive layout of roadside green spaces make them important green disaster mitigation nodes in highdensity areas of any city; hence, further improvements in their disaster mitigation functions would make the urban disaster prevention system more effective. In the present research, different types of roadside green spaces in the Gulou district of Nanjing were identified to establish a highly efficient urban disaster refuge green space system. A total of 35 built-up roadside green spaces were employed as the study site, and for field investigation and statistical analysis, 21 factors were selected from the aspects of spatial form, functional facilities, and surrounding environment. According to their disaster mitigation abilities, cluster analysis classified these roadside green spaces into four categories: complete type, potential type, centralized type, and broad type. Finally, by analyzing the characteristics of different types of roadside green spaces, corresponding optimization strategies were proposed. In comparison to previous investigations, our study focused on the quantitative evaluation of disaster mitigation and risk protection function of roadside green spaces. In the future, the obtained results will serve as important scientific references to the planning and construction of green spaces in high-density areas of Nanjing, China.
\end{abstract}

Keywords: roadside green space, high-density urban area, disaster consequence mitigation and evacuation, green infrastructure, cluster analysis, Nanjing.

\section{Introduction}

High-density urban areas manifest high population density and conspicuous infrastructural diversity. Urban green spaces play a key role in supporting activities of various social groups (Chen \& Chang, 2015); however, such areas are generally considered to have high disaster risks; hence, significant attention should be paid to the planning of a disaster mitigation system. Green spaces, because of their functional characteristics, are ideal for shelter and evacuation during natural and man-made disasters. Green spaces that are closer to residential areas, especially roadside green spaces, possess some important functional facilities including evacuation guidance, emergency evacuation, and temporary evacuation (Feltynowskia et al., 2018; Kita, 2017; Stessens, Khan, Huysmans, \& Canters, 2017). According to existing effective construction analysis, roadside green spaces should improve following three aspects of disaster mitigation and evacuation: 1. publicize the functions of disaster mitigation and evacuation system to every resident in a city, 2 . make the conversion between usual and disaster situation faster, and 3. make roadside green spaces more convenient to use for disaster evacuation. Therefore, the following steps should be adopted to establish an effective disaster mitigation system: 1. Carry out systematic analysis and scientific evaluation of disaster mitigation abilities of roadside green spaces; 2. Put forward relevant suggestions for improvement, and 3. enhance the functions of disaster consequence mitigation.

In the current study, field investigation and cluster analysis were employed to analyze disaster mitigation abilities of roadside green spaces.

1) After analyzing previous reports and conducting a field investigation, 21 factors were constructed from

${ }^{*}$ Corresponding author. E-mail: wjfei@njfu.edu.cn 
the perspectives of surrounding environment, spatial form, and functional facilities.

2) Based on selected factors, data were collected to clarify the present situation of roadside green spaces in the Gulou district.

3) Cluster analysis was used to classify roadside green spaces based on their disaster consequence mitigation and evacuation abilities.

4) Suggestions were proposed to improve the of green spaces based on classification results.

Existing studies on disaster mitigation mainly focused on four aspects: classification, theoretical construction, practical application, and experience summary. Different mathematical methods and information processing techniques, such as geographic information system, virtual simulation technology, multi-level analysis, evaluation model for disaster mitigation, were introduced to make the research more scientifically accurate (Khayal, Pradhananga, Pokharel, \& Mutlu, 2015; Koukis, Kelman, \& Ganapati, 2016; Mohammed, 2018).

In addition, based on different types and features of land use and disaster, many countries have developed green space disaster consequence mitigation and evacuation systems in combination with urban disaster prevention space systems (Fan, Xu, Yue, \& Chen, 2017) and have applied these systems to urban parks, squares, and other open spaces. The theory and practice of green space disaster prevention, which can be adaptive to regional characteristics, were formed through the processes of entirety to individuals, space to elements, and construction to operation. Europe and the United States have focused more effort on spatial planning, evacuation optimization, and rescue facility management (Fernandez et al., 2011; Iizuka, Xuan, \& Kondo, 2015; Nakamura, Umeki, \& Kato, 2016). Japan emphasized the development of disaster prevention parks, which are considered basic facilities for consequence mitigation of earthquake and other disasters (Chang, 2010; Elburz, Nijkamp, \& Pels, 2017; Satou, Koshizawa, \& Sakai, 2008).

Domestic research on disaster refuge green space mainly focused on spatial planning and disaster sequence; however, quantitative evaluation and classification of disaster mitigation abilities of green spaces were rarely carried out. At present, no unified definition for disaster mitigation of green spaces can be found; hence, a corresponding construction standard is also not yet formed. However, some regions have prepared local standards to satisfy local conditions.

Sichuan province of China is an earthquake-prone area, and its security facilities are relatively complete. According to "Sichuan Province Urban Hazard Prevention and Hazard Greenland Planning Guidelines", disaster refuge green spaces can be divided into dotted disaster refuge green spaces, linear disaster refuge green spaces, and planar disaster refuge green spaces based on their spatial forms. In addition, according to the system of disaster consequence mitigation and disaster relief, green spaces can be further divided into four categories: first-level disaster mitigation site, second-level disaster mitigation site, refuge channel, and disaster relief channel. Moreover, some scholars classified disaster refuge green spaces based on their locations and scales as well as the time sequence of disaster. Hence, disaster refuge green spaces can be divided into pre-disaster defensive green spaces, emergency shelter and disaster mitigation green spaces, fixed shelter and disaster mitigation green spaces, central shelter and disaster mitigating green spaces, countryside shelter and disaster mitigating green spaces, green evacuation corridors, and green isolation belts.

"Prevention" is the key aspect to develop an effective disaster mitigation and risk protection green space (González, Monsalve, Moris, \& Herrera, 2018). In large and medium cities, the principle of "prevention first, combining defense and relief", which emphasizes the combined positive effects of non-disaster and disaster situations, is the main approach of a city to resist disasters (Daniels et al., 2018; Ye, Hu, \& Li, 2018). The present study is a comprehensive assessment of disaster mitigation abilities of green spaces and provides a strong basis for the optimization of roadside green space constructions.

\section{Research process}

\subsection{Study site}

Nanjing is a regional center in the southeastern part of China (Figure 1) and possesses an area of 6587 square kilometers and a population of 818 million; hence, as a result of high population density, Nanjing often encounters some major problems including high degree of fragmentation, very limited green spaces, and weak accessibility and connectivity (Gong, Zheng, \& Ng, 2016). In the present study, the case of Nanjing Gulou district was considered. Gulou district is situated in the downtown area of Nanjing and possesses high building density, complex and diverse infrastructures, and high population density (243.4 people/ ha). According to the World population density ranking of 2017, Gulou can be considered as a typical example of urban high-density area (Nanjing Urban Planning Bureau, 2017). Nanjing is located in the middle and the lower reaches of the Yangtze River in the Yellow Sea seismic belt, thus this area is very prone to medium-strong earthquakes. Four seismic faults were detected in Nanjing, and two of them have caused strong earthquakes. Although they are currently considered as hidden faults, the probability of future earthquakes is very high. In addition, according to the latest statistical data, Nanjing experiences 1675 fire incidents every year, and most of these reported fires occurred in the Gulou district. Therefore, Nanjing Gulou district can be considered as a representative case for disaster mitigation analysis (Nanjing Public Security Fire Bureau, 2017).

Gulou district contains 13 comprehensive parks (17.6\% of total green spaces), 7 residential area parks (9.5\%), 7 topic parks (9.5\%), 12 ribbon parks (16.2\%), and 


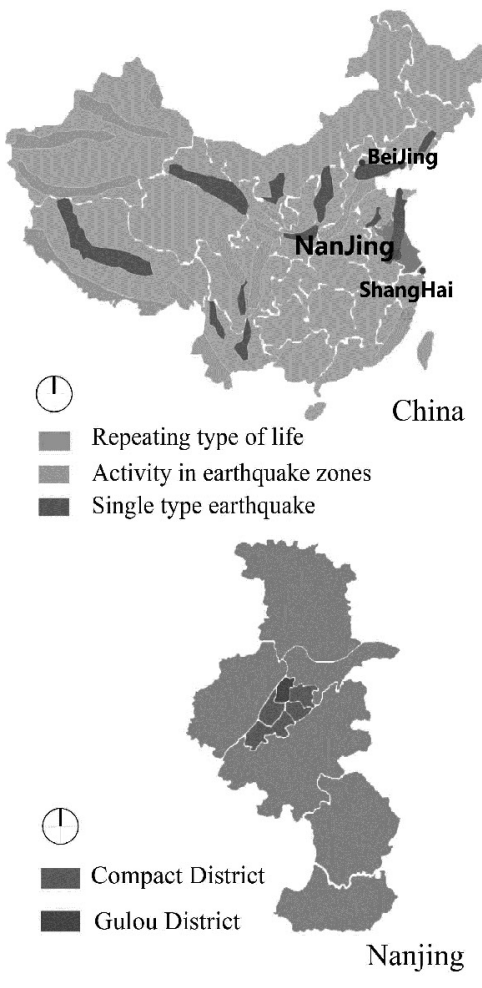

Nanjing

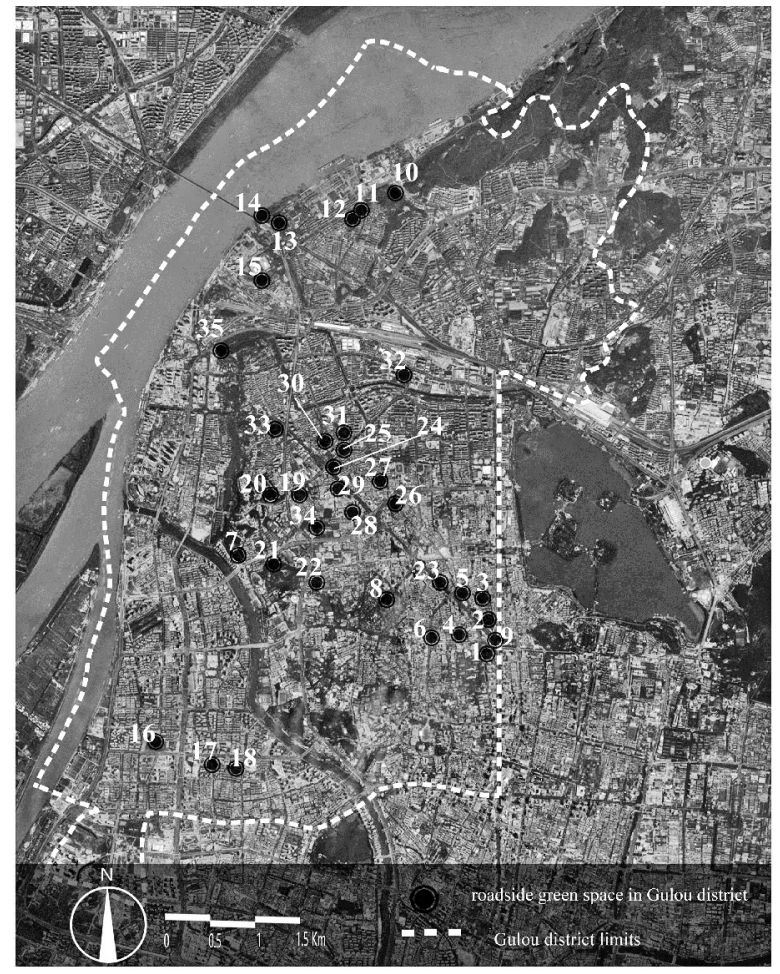

The distribution of roadside green space in Gulou district

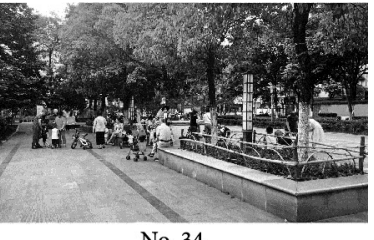

No. 34

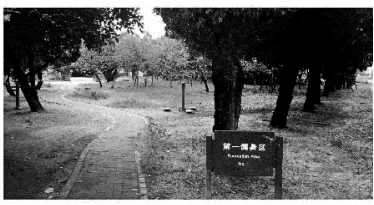

No. 14

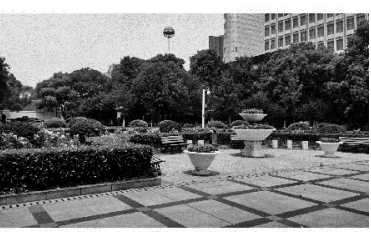

No. 9

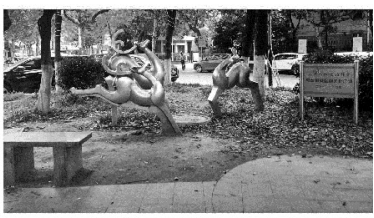

No. 26

Figure 1. Research area and different types of roadside green spaces

35 roadside green spaces $(47.3 \%)$ (Table 1$)$. In terms of disaster mitigation, Gulou has one fixed disaster prevention park and four emergency disaster prevention parks. In addition, four emergency disaster prevention plazas have been already constructed; however, they have failed to meet the requirements of disaster mitigation. Fortunately, roadside green spaces in the Gulou district can be conveniently used for emergency shelters and disaster mitigation.

Table 1. Roadside green spaces in Gulou

\begin{tabular}{|c|l|}
\hline No. & \multicolumn{1}{|c|}{ Location } \\
\hline 1 & Dazhong Pavilion Park \\
\hline 2 & $\begin{array}{l}\text { Roadside green space on the south side of the Zifeng } \\
\text { Tower }\end{array}$ \\
\hline 3 & The square in front of the Zifeng Tower \\
\hline 4 & $\begin{array}{l}\text { Roadside green space on the south side of the Gulou } \\
\text { Park }\end{array}$ \\
\hline 5 & $\begin{array}{l}\text { Roadside green space beside the high school affiliated } \\
\text { to Nanjing University }\end{array}$ \\
\hline 6 & $\begin{array}{l}\text { Yunnan road and West Bridge intersection green } \\
\text { space }\end{array}$ \\
\hline 7 & $\begin{array}{l}\text { Ninghai Road and Guangzhou Road intersection } \\
\text { green space }\end{array}$ \\
\hline 8 & Green space on the opposite side of the Airsun mall \\
\hline 9 & Drum Tower Square \\
\hline 10 & $\begin{array}{l}\text { jin Yan road and Bao Yan Road intersection green } \\
\text { space }\end{array}$ \\
\hline
\end{tabular}

Continued Table 1

\begin{tabular}{|c|l|}
\hline No. & \multicolumn{1}{|c|}{ Location } \\
\hline 11 & $\begin{array}{l}\text { Green space along the south side of the Yanjiang } \\
\text { Road }\end{array}$ \\
\hline 12 & Green space on the south side of the Yanjiang Road \\
\hline 13 & $\begin{array}{l}\text { Green space on the south side of the Baota Bridge } \\
\text { (on the West Street) }\end{array}$ \\
\hline 14 & Bridge Park \\
\hline 15 & $\begin{array}{l}\text { Jiangdong North Road and Longyuan South Road } \\
\text { intersection green space }\end{array}$ \\
\hline 16 & $\begin{array}{l}\text { Qingiang road and Dongbao Road intersection green } \\
\text { space }\end{array}$ \\
\hline 17 & $\begin{array}{l}\text { Northwestern corner at the intersection of Qingjiang } \\
\text { road and Hanzhoung Gate Street }\end{array}$ \\
\hline 18 & $\begin{array}{l}\text { Northwestern corner at the intersection of } \\
\text { Hanzhoung Gate Street and Qingjiang South Road }\end{array}$ \\
\hline 19 & Green space on the Hu Ju North Road \\
\hline 20 & $\begin{array}{l}\text { The wall mouth at the intersection of Mo Fan West } \\
\text { Road and Stone City }\end{array}$ \\
\hline 21 & Green space beside the Beiermei Plastic Hospital \\
\hline 22 & $\begin{array}{l}\text { Green space on the opposite side of the Nanjing Arts } \\
\text { Institute }\end{array}$ \\
\hline 23 & Tongiiaxiang and Dingiiaqiao intersection \\
\hline 24 & Longyin Square \\
\hline 25 & Zhongshan North Road and Beisiweitou intersection \\
\hline 26 & Matai Street and Hong Bridge intersection \\
\hline 27 & Sibeihou Road and Pinganli intersection \\
\hline 28 & Sanpailou street and Xinmofan road intersection \\
\hline & \\
\hline
\end{tabular}


End of Table 1

\begin{tabular}{|c|l|}
\hline No. & \multicolumn{1}{|c|}{ Location } \\
\hline 29 & Zhongshan North Road new city center green space \\
\hline 30 & Fujian Road and Sanpailou Street intersection \\
\hline 31 & $\begin{array}{l}\text { Between the east side of the Railway North Street and } \\
\text { Hongmiao lane (beside the moat) }\end{array}$ \\
\hline 32 & $\begin{array}{l}\text { The west side of the Railway North Street (beside the } \\
\text { moat) }\end{array}$ \\
\hline 33 & $\begin{array}{l}\text { The triangle at the intersection of Railway North } \\
\text { Street (east side) and Hongmiao Lane }\end{array}$ \\
\hline 34 & Railway North Street Square \\
\hline 35 & Stone City Road, Shuimu Qinhuai \\
\hline
\end{tabular}

\subsection{Factors for evaluating disaster mitigation ability}

According to the proposal of "Nanjing Green Space System Planning (2013-2020)", a site investigation on 35 roadside green spaces in the Gulou district was conducted for the present analysis.

\subsection{Selection of the factors}

According to previous research, factors that affect the ability of disaster consequence mitigation and evacuation in roadside green spaces can be divided into two levels: internal and external.

Internal factors represent both spatial forms and functional facilities. Spatial forms, such as roadside green space areas, interior lawn areas, and green pavement areas, reflect the capacity of evacuation and refuge. Functional facilities can be also divided into two categories: (i) roadside green space facilities, such as security monitors, toilets, lighting devices, water supply facilities, underground

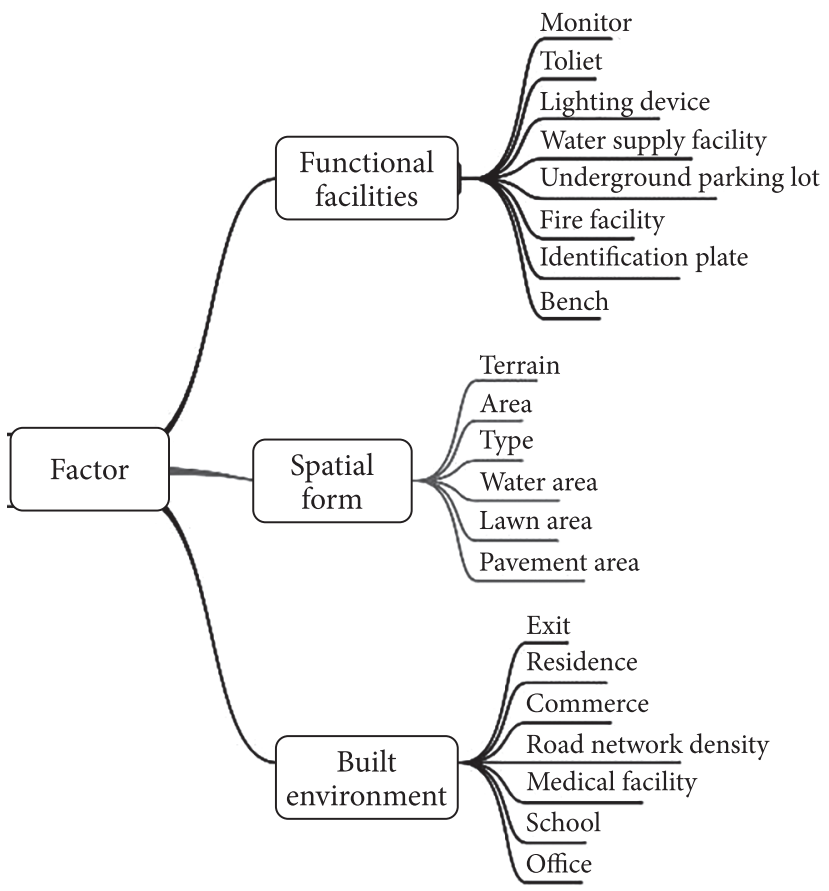

Figure 2. Index tree diagram parking lots, firefighting facilities, identification plates, can be directly used for disaster mitigation and (ii) auxiliary facilities, such as benches, entrances/exits, and other necessary services.

External factors directly affect the accessibility of roadside green spaces, the distribution of surrounding population, and the implementation of evacuation method. These factors include traffic system, residential areas, commercial buildings, hospitals, schools, playgrounds, government and enterprise buildings, and road network density.

Hence, based on the comprehensive analysis, 21 factors (Figure 2) were selected for the current research.

\subsection{Data collection}

In the present analysis, data were collected according to the proposed index framework (Appendix: Tables 2, 3, 4). First, the total number of functional facilities in each roadside green space was counted, and then all facilities that belonged to urban spatial forms and built-environment were marked.

\section{Results}

\subsection{Analysis of disaster mitigation abilities of roadside green spaces in Gulou district}

Data processing and statistical analysis were carried out for sorting functional facilities, spatial forms, and builtenvironment (Figure 3). Functional facilities mainly contained benches, security monitors, toilets, water supply facilities, underground parking lots, firefighting facilities, and identification plates. It is evident from the obtained results that benches were adequate to fulfill demands in all roadside green spaces; however, the situations of other functional facilities were dangerous. More than $70 \%$ roadside green spaces lacked toilets, water supply facilities, underground parking lots, and identification plates; more than $75 \%$ green spaces had less than 4 firefighting facilities; and $72 \%$ of green spaces had less than 19 lighting devices. In terms of spatial forms, $63 \%$ of roadside green spaces had a flat terrain with an average area of about 1 hectare, and pavement areas and lawn areas were ranged from $0.2 \sim 0.4$ hectare (ha). Moreover, about $40 \%$ roadside green spaces manifested a height difference of $0 \sim 0.6 \mathrm{~m}$. In addition, $37 \%$ roadside green spaces had open entrance; $69 \%$ green spaces had a road network density of $4-6 \mathrm{~km} /$ $\mathrm{km}^{2} ; 37 \%$ roadside spaces manifested 7-9 settlements; $31 \%$ green spaces had $10-12$ commercial points; and $26 \%$ roadside spaces did not have a medical point.

\subsection{Cluster analysis}

Before starting the cluster analysis, data were arranged and sorted (Appendix: Tables 5, 6, 7). Preprocessed data were first inputted into a statistical analysis software package (SPSS 20.0) to obtain standardized data, and then the cluster provided by SPSS was adopted to classify the obtained standardized data (Figure 4). All samples were classified 


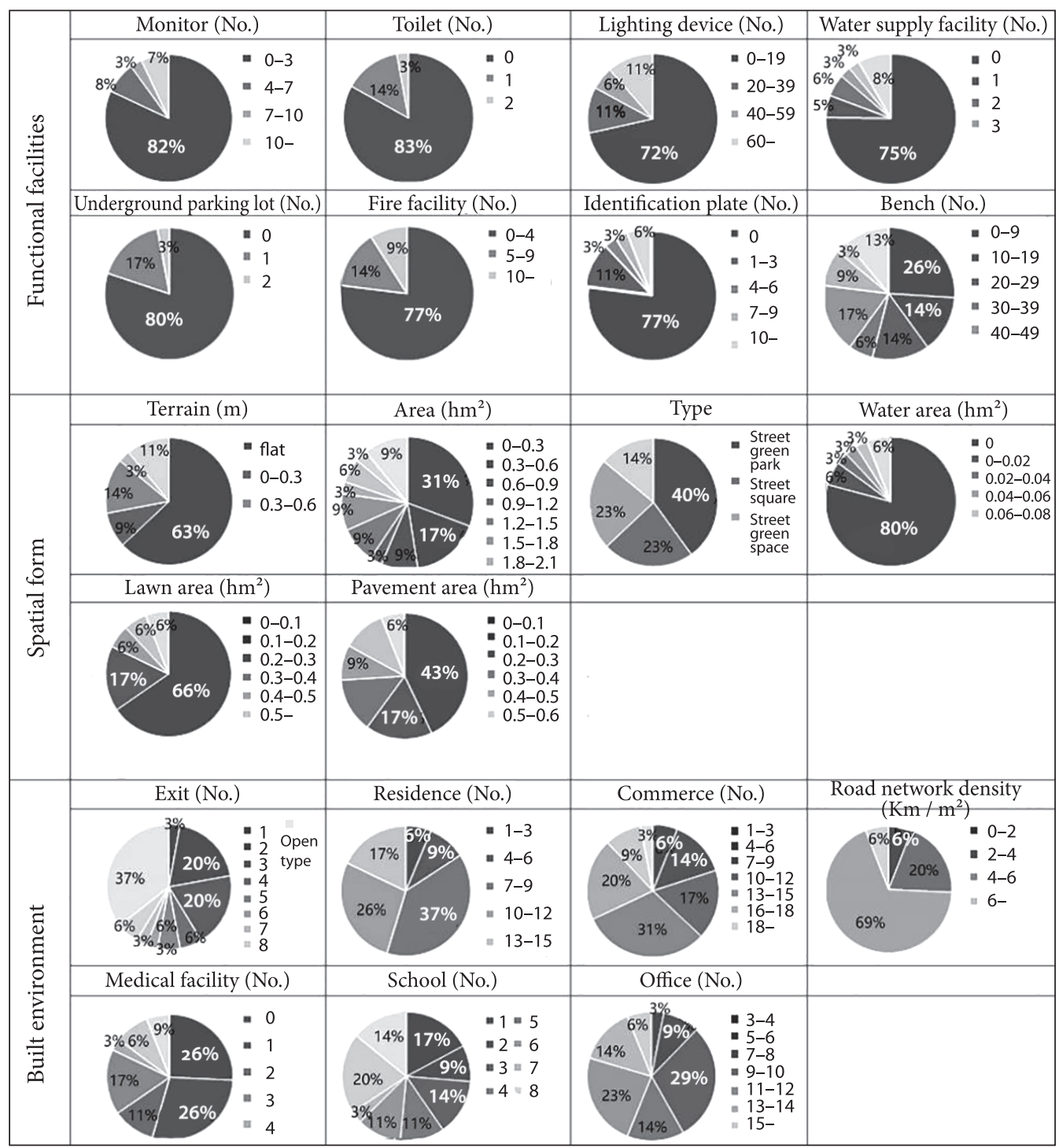

Figure 3. Data statistics

into 4 groups with a group distance of 20. It should be noted that different cluster analysis methods may yield different results even for the same initial set of data. The results of this study are based on the above methods.

\subsection{Classification of road side green areas}

In the current study, fire, earthquake, and their secondary disasters were targeted to perform disaster mitigation and evacuation analysis. Roadside green spaces of Gulou were classified into 4 groups, such as completed type, potential type, centralized type, and broad type, according to their disaster mitigation abilities.

\section{(1) Complete type (Cluster 1)}

Roadside green spaces with serial numbers 18, 24, 29, and 35 belonged to the complete type. The standardized score for each variable revealed that the average area of complete type was close to the average area of all samples. The
Dendrogram using Average Linkage (between groups)

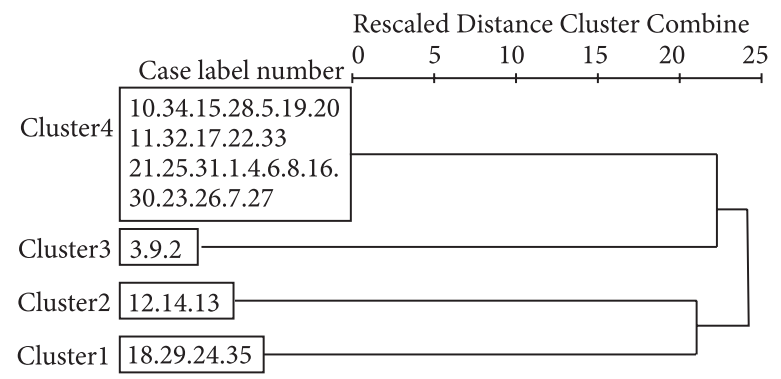

Figure 4. Pedigree diagram of system cluster

complete type contained the highest level of functional facilities, such as internal monitors, lighting devices, firefighting facilities, identification plates, and benches. As complete type roadside green spaces were surrounded by residential and office buildings, they were often equipped 
with underground parking lots and other utilization facilities. Therefore, it can be inferred that complete type green spaces had comprehensive advantages among all 4 types (Figure 5a).

Generally, complete type green spaces were well constructed, convenient to access, and well-known.

However, some improvements in security should be made in the future. For example, the installation of lamp posts, which have a risk of collapse, should be prevented, and more entrances must be set to create more efficient disaster refuge green spaces.

\section{(2) Potential type (Cluster 2)}

Roadside green spaces with serial numbers 12,13 , and 14 belonged to the potential type, which manifested the characteristics of convenient entrance and good passing ability (necessary for quick evacuation of people). Potential type green spaces had flat terrains and also water areas with an area larger than 1 ha. These green spaces were commonly located in areas with relatively low population and building densities and lower traffic flow. The spatial form indicator exhibited a strong potential; hence, these green spaces were named as "potential type" (Figure 5b).

As areas of potential type roadside green spaces are large enough to be used as evacuation areas, attention should be paid to the planning of evacuation route and evacuation education during the construction of this type of green space. The effective planning will make potential type roadside green spaces more accessible in an incident of disaster.

\section{(3) Centralized type (Cluster 3)}

Roadside green spaces with serial numbers 2,3 , and 9 belonged to the centralized type, which located in areas with high population and building densities. This type of green space generally had a complex traffic environment and was surrounded by a lot of commercial facilities, hospitals, and schools. Centralized type roadside green spaces had the largest area, the largest service radius, and the most comprehensive facilities among all 4 groups. These green spaces were often constructed in the form of a square, and their surrounding environments had a relatively high level of functional facilities; therefore, they were named as "centralized type" (Figure 5c).

Centralized type roadside green spaces had a relatively larger area for disaster evacuation. Therefore, they have the best ability of disaster mitigation and evacuation. Hence, more attention should be paid to evacuation routes and emergency equipment in order to improve rescue efficiency.

\section{(4) Broad type (Cluster 4)}

Broad type is the most common one (Figure $5 \mathrm{~d}$ ) and contained other 25 roadside green spaces. 25 samples were divided into 2 groups: (i) small roadside green spaces with less than 1 ha area, they can be used only to provide shelter and (ii) The other group consisted of large roadside parks and squares, which were located at the corners of the intersections or in human settlements. These green spaces had a good accessibility and were developed to improving greening and cultural landscape; however, some insufficiencies in internal facilities were noticed; commonly, there were only a small number of benches and lighting facilities. These roadside green spaces were small in size and also were broadly distributed. Broad type green spaces can play a role of temporary refuge as well as can act a connector for all different scales of refuges. The major shortcomings of these green spaces are the lack of evacuation logo and publicity. Therefore, construction and functional facilities should be improved and more attention should be paid to publicity works.

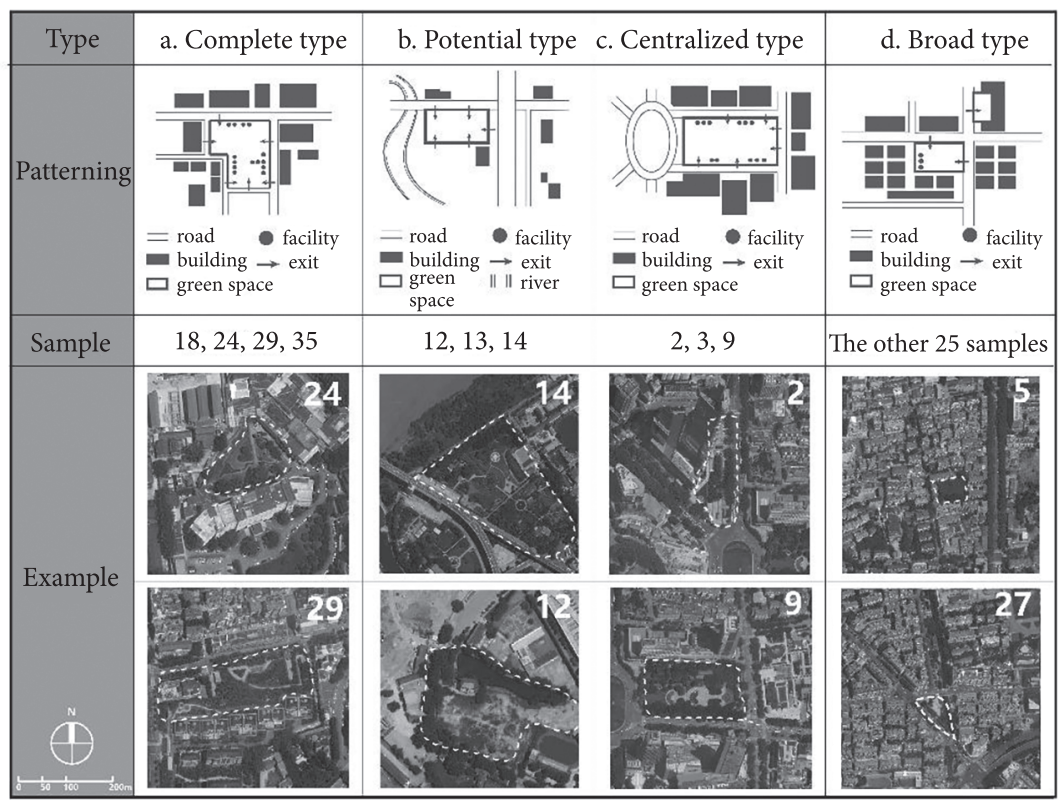

Figure 5. Classification result 


\section{Discussion}

\section{Applicability and suitability of the proposed method}

Nanjing, a key central city located in the region of Yangtze River Delta, features outstanding urbanization. However, its green area per capita is lower than that of Shanghai and Tokyo, as well as other metropolises both at home and abroad (Wang, 2008). Due to its regional characteristics and disaster environment, Gulou district is an ideal example to analyze disaster mitigation and evacuation process. Due to high population and building densities, green spaces in the Gulou district manifest a dotted distribution. The construction of green spaces is showing an accelerating trend, and green spaces built in different periods have been integrated with each other. In comparison to other urban areas, green spaces in Gulou exhibits more complex structures. Therefore, the disaster mitigation abilities of green spaces are generally affected by the superposition of various factors, thus during the research on green spaces in Gulou, attentions were paid on functional facilities, spatial forms, and surrounding environment to carry out quantitative analysis and evaluation.

Most of the existing studies on the classification of disaster mitigation green spaces mainly focused on qualitative analysis, but few quantitative analysis. The research process itself lacks scientific support. In terms of the largescale mechanism of Urban Disaster Mitigation System, contingency plan of disaster management is deemed as the most consummate part. The United States is regarded as a typical representative in the construction of contemporary emergency system, and its National Incident Management System (NIMS) is also known as a model among the institutions engaged in emergency management (Fernandez et al., 2011). In order to effectively deal with various frequently occurred natural disasters, Japan has established a disaster prevention system covering the three main aspects of disaster prevention, emergency response and reconstruction (Feng, Zhang, Shao, \& Meng, 2016). Moreover, Turkey has formulated a coordinated management mechanism to response to the situation before and after urban disasters (Caymaz, Akyon, \& Erenel, 2013). These mature theoretical systems, which can be referred to as guidance and premise, play their guiding role on the macro level. Some innovative researches have been conducted from the angle of evacuation from urban disaster, for example, resilient evacuation planning for urban disaster mitigation on the assumption of the Cell-Transmission Model (CTM) (Kimms \& Maiwald, 2018) and disaster evacuation management supported by RFID (Radio Frequency Identification) technology (Shi, Ye, Wang, \& Fei, 2018).

However, situated in the middle level of the whole mechanism, the planning and construction of spaces employed for urban disaster mitigation are relatively weak. In view of the fact that urban green space occupies a significant role in the spaces employed for disaster mitigation, the study aims to optimize the capability of roadside green spaces displayed for disaster mitigation from the perspective of urban green spaces planning, so that it can fill in the gap of scientific literature in this field.

In previous studies on the similar areas, some scholars carried out in-depth analysis of the green resources in the research area, thus improving the layout of green spaces in disaster mitigation and the direction for the advancement of mitigation capability shown by green spaces in disaster (Zhu \& Jia, 2012). Furthermore, some scholars employed the AHP model to construct the evaluation system to estimate the emergency refuge function of urban green spaces, calculated the scores obtained and sorted them out after defining the coefficient. This method attaches its importance to analyze the disaster mitigation ability of a single green space (Hong, Yang, \& Zheng, 2013). Some scholars even adopted the technology of GIS network analysis by combining GIS with spatial optimization model so as to form a suitable evaluation index system for the disaster mitigation of urban green space, thus providing a micro-scale classification (Ye, Wang, Xu, Chen, \& Huang, 2010).

The clustering analysis employed in this paper is a method to collect data on a similar basis for classification by comparison, and the difference between clustering and general classification is that the classes demanded by clustering are unknown, which often leads to original conclusions (Nagpal, Jatain, \& Gaur, 2013). In previous studies of this field, some scholars employed clustering analysis to reduce data and analyze the horizontal spatial measurement of landscape (Liang, Chen, \& Zhang, 2017), and some adopted cluster analysis to make a detailed division of specific spatial types (Wang, Deguchi, Minoura, \& Sakai, 2012). The common ground is that useful information can be mined from complex and huge data of landscape architecture, a comprehensive interdisciplinary field. Thus, the system structure can be displayed more clearly so that further work can be carried out in a targeted way.

The present study makes a meticulous classification of disaster mitigation abilities possessed by the built-up green spaces in a quantitative way according to field investigations conducted in advance. The appropriateness and typicality of the method lie in:

1) Apart from ensuring the integrity of the data and quantifying the basic attributes of the green space at roadside in Gulou district, it is conductive to forming a direct and objective comparison between the samples.

2) The obtained results conform to the actual situation of urban disaster mitigation, and each finding is verified by actual cases. Meanwhile, it is more efficient and applicable to employ the clustering method to study the green space sample in face of the diversified types and the increasing area of urban green spaces.

3) As the classification and standard model can break away from the existing classification system of the disaster prevention of green space, it is indeed an innovative attempt. 


\section{Limitations}

All 21 explanatory factors were selected from the aspects of surrounding environment, spatial form, and infrastructure; hence, the conducted study was not comprehensive enough. Management mechanism, human behavior, and some other relevant elements were not considered. In addition, our research evaluated the disaster mitigation ability of single green space, thus the optimization of disaster mitigation mechanism within specific regions was not performed.

The aforesaid problems will be circumvented in the next phase of our research. The variety and quantity of samples should be increased, and the method of selecting factors should be more systematic in order to improve the accuracy of evaluation and classification. Although some problems still exist, our study reflects its objectivity in comparison to previous qualitative methods. The comprehensive analysis and evaluation of disaster mitigation abilities of roadside green spaces can provide a basis for green space planning with respect to spatial layout, infrastructure, and functionality.

\section{Broader theoretical and practical significance}

In future research, evacuation simulation software, such as STEPS or Pathfinder, will be introduced into the regional evacuation simulation to evaluate service radii and carrying capacities of four types of roadside green spaces. The accuracies of obtained results will be assessed by analyzing the effectiveness of various factors, and the consistency between green space positioning and research expectation will also be validated. During simulation, software will supplement people activities and the path of crowd refuge, and consequently, enhance the practicality of research results.

Although the current research method was implemented on a small area, it can be applied to other types of green spaces including urban integrated parks and banded green spaces. In the future, a high-efficient urban disaster refuge green space system with reasonable composition will be established.

\section{Conclusions}

Based on the analysis of disaster consequence mitigation abilities of 35 roadside green spaces in the Gulou district of Nanjing, the following inferences can be drawn.

1) To create a classification system of disaster mitigation abilities of roadside green spaces after reviewing previous researches on Gulou. The evaluation index of 21 factors was proposed in terms of three aspects, such as spatial form, functional facilities, and surrounding environment.

2) The status of 35 roadside green spaces in the Gulou district was obtained based on data processing and statistical analysis. In terms of spatial form, 60\% roadside green spaces were flat with an average area of about 1 ha. However, total area, pavement area, and lawn area of all roadside green spaces were significantly different. More than $70 \%$ roadside green spaces lacked toilets, water supply facilities, underground parking lots, and identification plates. In addition, 37\% roadside green spaces had an open entrance; the density of surrounding road network was suitable for disaster mitigation and evacuation, and residential and commercial points were distributed to a certain extent.

3) All roadside green spaces were classified into 4 groups (complete type, potential type, centralized type, and broad type) using cluster analysis and their roles in disaster mitigation were explained. Finally, recommendations to improve the functionality of disaster mitigation system based on different characteristics of each green space group were proposed.

In the future, the potential of the present study will be applied to establish a highly efficient urban disaster refuge green space system with reasonable composition.

\section{Author contributions}

Conceived and designed the experiments: WF. Performed the experiments: ZJ CW. Analyzed the data: WF. Contributed materials/analysis tools: PD TS. Contributed to the writing of the manuscript: WF ZJ JY. Revised and approved the final version of the paper: PD.

\section{Funding}

This work was financially supported by the National Natural Science Foundation of China under Grant No. C161202.

\section{References}

Caymaz, E., Akyon, F. V., \& Erenel, F. (2013). A model proposal for efficient disaster management: The Turkish sample. Procedia - Social and Behavioral Sciences, 99, 609-618. https://doi.org/10.1016/j.sbspro.2013.10.531

Chang, S. E. (2010). Urban disaster recovery: a measurement framework and its application to the 1995 Kobe earthquake. Disasters, 34(2), 303-327. https://doi.org/10.1111/j.1467-7717.2009.01130.x

Chen, J., \& Chang, Z. (2015). Rethinking urban green space accessibility: Evaluating and optimizing public transportation system through social network analysis in megacities. Landscape \& Urban Planning, 143(3), 150-159. https://doi.org/10.1016/j.landurbplan.2015.07.007

Daniels, B., Zaunbrecher, B. S., Paas, B., Ottermanns, R., Ziefle, M., \& Roßnickoll, M. (2018). Assessment of urban green space structures and their quality from a multidimensional perspective. Science of the Total Environment, 615, 1364-1378. https://doi.org/10.1016/j.scitotenv.2017.09.167

Elburz, Z., Nijkamp, P., \& Pels, E. (2017). Public infrastructure and regional growth: Lessons from meta-analysis. Journal of Transport Geography, 58, 1-8. https://doi.org/10.1016/j.jtrangeo.2016.10.013 
Fan, P., Xu, L., Yue, W., \& Chen, J. (2017). Accessibility of public urban green space in an urban periphery: The case of Shanghai. Landscape \& Urban Planning, 165, 177-192. https://doi.org/10.1016/j.landurbplan.2016.11.007

Feltynowskia, M., Kronenberga, J., Bergierb, T., Kabischc, N., Łaszkiewicza, E., \& Strohbachd, M. W. (2018). Challenges of urban green space management in the face of using inadequate data. Urban Forestry \& Urban Greening, 31, 56-66. https://doi.org/10.1016/j.ufug.2017.12.003

Feng, Y., Zhang, L., Shao, M., \& Meng, Q. (2016). Discussion on the construction of disaster prevention green infrastructure network planning. AER-Advances in Engineering Research, 4, 1211-1216. https://doi.org/10.2991/nceece-15.2016.215

Fernandez, A. R., Studnek, J. R., Margolis, G. S., Mac, C. J., Bentley, M. A., \& Marcozzi, D. (2011). Disaster preparedness of nationally certified emergency medical services professionals. Academic Emergency Medicine, 18(4), 403-412. https://doi.org/10.1111/j.1553-2712.2011.01030.x

Gong, F., Zheng, Z. C., \& Ng, E. (2016). Modeling elderly accessibility to urban green space in high density cities: A case study of Hong Kong. Procedia Environmental Sciences, 36, 90-97. https://doi.org/10.1016/j.proenv.2016.09.018

González, D. P., Monsalve, M., Moris, R., \& Herrera, C. (2018). Risk and resilience monitor: Development of multiscale and multilevel indicators for disaster risk management for the communes and urban areas of Chile. Applied Geography, 94, 262-271. https://doi.org/10.1016/j.apgeog.2018.03.004

Hong, T. T., Yang, W. X., \& Zheng, Y. S. (2013). Evaluation on the function of urban green space emergency shelter based on AHP. Journal of Fujian Forestry Science \& Technology, 40(01), 133-137.

Iizuka, S., Xuan, Y., \& Kondo, Y. (2015). Impacts of disaster mitigation/prevention urban structure models on future urban thermal environment. Sustainable Cities \& Society, 19, 414420. https://doi.org/10.1016/j.scs.2015.06.008

Khayal, D., Pradhananga, R., Pokharel, S., \& Mutlu, F. (2015). A model for planning locations of temporary distribution facilities for emergency response. Socio-Economic Planning Sciences, 52, 22-30. https://doi.org/10.1016/j.seps.2015.09.002

Kimms, A., \& Maiwald, M. (2018). Bi-objective safe and resilient urban evacuation planning. European Journal of Operational Research, 269(3), 1122-1136.

https://doi.org/10.1016/j.ejor.2018.02.050

Kita, S. M. (2017). Urban vulnerability, disaster risk reduction and resettlement in Mzuzu city, Malawi. International Journal of Disaster Risk Reduction, 22, 158-166. https://doi.org/10.1016/j.ijdrr.2017.03.010

Koukis, T., Kelman, I., \& Ganapati, N. E. (2016). Greece-Turkey disaster diplomacy from disaster risk reduction. International Journal of Disaster Risk Reduction, 17, 24-32. https://doi.org/10.1016/j.ijdrr.2016.03.004

Liang, H., Chen, D., \& Zhang, Q. (2017). Assessing Urban Green Space distribution in a compact megacity by landscape met- rics. Journal of Environmental Engineering \& Landscape Management, 25(1), 64-74.

https://doi.org/10.3846/16486897.2016.1210157

Mohammed, M. P. (2018). Disaster risk reduction and management of Tarlac City. Procedia Engineering, 212, 77-84. https://doi.org/10.1016/j.proeng.2018.01.011

Nagpal, A., Jatain, A., \& Gaur, D. (2013). Review based on data clustering algorithms. In 2013 IEEE Conference on Information \& Communication Technologies, 11-12 April 2013, Thuckalay, Tamil Nadu, India. IEEE. https://doi.org/10.1109/CICT.2013.6558109

Nakamura, H., Umeki, H., \& Kato, T. (2016). Importance of communication and knowledge of disasters in communitybased disaster-prevention meetings. Safety Science, 99, 235243. https://doi.org/10.1016/j.ssci.2016.08.024

Nanjing Public Security Fire Bureau. (2017). Retrieved from https://www.nj119.com.cn/media_jlwb.htm

Nanjing Urban Planning Bureau. (2017). Retrieved from https:// www.njghj.gov.cn/NGWeb/Page/Index.aspx

Satou, Y., Koshizawa, A., \& Sakai, A. (2008). The planning of the fire prevention boulevards and park in otaru in meiji era. Aij Journal of Technology \& Design, 14(27), 321-324. https://doi.org/10.3130/aijt.14.321

Shi, Y., Ye, J., Wang, M., \& Fei, W. (2018). Application of internet of things technology to the design of disaster prevention and refuge function in urban integrated parks. Journal of Nanjing Forestry University (Natural Sciences Edition), 42(04), 187192. https://10.3969/j.issn.1000-2006.201712011

Stessens, P., Khan, A. Z., Huysmans, M., \& Canters, F. (2017). Analysing urban green space accessibility and quality: A GISbased model as spatial decision support for urban ecosystem services in Brussels. Ecosystem Services, 28, 328-340. https://doi.org/10.1016/j.ecoser.2017.10.016

Wang, C., Deguchi, A., Minoura, E., \& Sakai, T. (2012). Transformation and classification of wall spaces in Nanjing, China. Journal of Architecture Planning and Environmental Engineering, 77(672), 385-391. https://doi.org/10.3130/aija.77.385

Wang, J. (2008). Green spot in the high density urban area A case study of Nanjing Old Town. Modern Urban Research, (04), 69-73.

Ye, C., Hu, L., \& Li, M. (2018). Urban green space accessibility changes in a high-density city: A case study of Macau from 2010 to 2015. Journal of Transport Geography, 66, 106-115. https://doi.org/10.1016/j.jtrangeo.2017.11.009

Ye, M., Wang, J., Xu, S., Chen, Z., \& Huang, J. (2010). Establishment and application of urban green park to earthquake disaster prevention and refuge planning method. Advances in Intelligent Systems Research, 13, 209.

Zhu, L. J., \& Jia, Y. (2012). Construction of green space system of disaster-prevention in old districts of Zhengzhou City. Advanced Materials Research, 450-451, 1314-1317. https://doi. org/10.4028/www.scientific.net/AMR.450-451.1314 


\section{APPENDIX}

Table 2. Survey statistics of functional facilities

\begin{tabular}{|c|c|c|c|c|c|c|c|c|}
\hline \multirow{2}{*}{$\begin{array}{c}\text { Serial } \\
\text { num- } \\
\text { ber }\end{array}$} & \multicolumn{8}{|c|}{ Functional facilities } \\
\hline & Montior No. & Toliet No. & $\begin{array}{l}\text { Lighting } \\
\text { device No. }\end{array}$ & $\begin{array}{l}\text { Water supply } \\
\text { facility No. }\end{array}$ & $\begin{array}{l}\text { Underground } \\
\text { parking lot No. }\end{array}$ & $\begin{array}{l}\text { Fire facility } \\
\text { No. }\end{array}$ & $\begin{array}{c}\text { Identification } \\
\text { plate No. }\end{array}$ & Bench No. \\
\hline 1 & 0 & 1 & 22 & 3 & 0 & 25 & 1 & 12 \\
\hline 2 & 2 & 0 & 86 & 0 & 0 & 0 & 3 & 54 \\
\hline 3 & 9 & 0 & 40 & 13 & 1 & 9 & 20 & 40 \\
\hline 4 & 0 & 0 & 6 & 0 & 0 & 1 & 0 & 20 \\
\hline 5 & 1 & 0 & 3 & 0 & 0 & 0 & 0 & 8 \\
\hline 6 & 0 & 0 & 4 & 0 & 0 & 0 & 0 & 20 \\
\hline 7 & 0 & 0 & 0 & 0 & 0 & 0 & 0 & 4 \\
\hline 8 & 0 & 0 & 0 & 0 & 1 & 0 & 0 & 24 \\
\hline 9 & 6 & 1 & 150 & 35 & 0 & 0 & 0 & 39 \\
\hline 10 & 0 & 0 & 0 & 0 & 0 & 0 & 0 & 43 \\
\hline 11 & 0 & 0 & 0 & 0 & 0 & 0 & 0 & 29 \\
\hline 12 & 0 & 1 & 3 & 0 & 0 & 0 & 0 & 20 \\
\hline 13 & 0 & 0 & 0 & 0 & 0 & 0 & 0 & 0 \\
\hline 14 & 0 & 1 & 45 & 0 & 0 & 0 & 3 & 48 \\
\hline 15 & 1 & 0 & 2 & 0 & 0 & 0 & 0 & 11 \\
\hline 16 & 1 & 0 & 4 & 0 & 0 & 7 & 0 & 8 \\
\hline 17 & 0 & 0 & 5 & 0 & 0 & 1 & 0 & 33 \\
\hline 18 & 20 & 0 & 178 & 2 & 2 & 20 & 9 & 358 \\
\hline 19 & 0 & 0 & 0 & 0 & 0 & 1 & 0 & 62 \\
\hline 20 & 1 & 0 & 3 & 0 & 0 & 1 & 0 & 48 \\
\hline 21 & 1 & 0 & 0 & 0 & 0 & 7 & 0 & 0 \\
\hline 22 & 1 & 0 & 8 & 16 & 1 & 0 & 0 & 0 \\
\hline 23 & 2 & 0 & 8 & 1 & 0 & 0 & 0 & 0 \\
\hline 24 & 4 & 0 & 34 & 0 & 1 & 7 & 5 & 42 \\
\hline 25 & 0 & 0 & 0 & 0 & 0 & 0 & 0 & 0 \\
\hline 26 & 0 & 0 & 3 & 0 & 0 & 0 & 0 & 12 \\
\hline 27 & 0 & 0 & 0 & 1 & 0 & 5 & 2 & 56 \\
\hline 28 & 0 & 1 & 0 & 0 & 0 & 0 & 0 & 44 \\
\hline 29 & 4 & 0 & 28 & 4 & 1 & 2 & 0 & 161 \\
\hline 30 & 0 & 0 & 0 & 0 & 0 & 0 & 0 & 16 \\
\hline 31 & 1 & 0 & 0 & 0 & 0 & 0 & 0 & 50 \\
\hline 32 & 1 & 0 & 0 & 0 & 0 & 1 & 0 & 16 \\
\hline 33 & 1 & 0 & 2 & 0 & 0 & 0 & 0 & 0 \\
\hline 34 & 2 & 0 & 29 & 0 & 0 & 0 & 0 & 176 \\
\hline 35 & 30 & 2 & 148 & 2 & 1 & 13 & 11 & 80 \\
\hline
\end{tabular}


Table 3. Survey statistics of spatial form

\begin{tabular}{|c|c|c|c|c|c|c|}
\hline \multirow{2}{*}{$\begin{array}{c}\text { Serial } \\
\text { num- } \\
\text { ber }\end{array}$} & \multicolumn{6}{|c|}{ Spatial form } \\
\hline & Terrian, m & Area $\mathrm{hm}^{2}$ & Type & Water area, $\mathrm{hm}^{2}$ & Lawn area, $\mathrm{hm}^{2}$ & Pavement area, $\mathrm{hm}^{2}$ \\
\hline 1 & 4 & 0.26 & 0 & 0.004 & 0.02 & 0.15 \\
\hline 2 & 4 & 0.63 & 1 & 0 & 0.46 & 0.08 \\
\hline 3 & 0 & 2.38 & 3 & 0.047 & 0.13 & 0.50 \\
\hline 4 & 4 & 0.13 & 0 & 0 & 0.15 & 0.34 \\
\hline 5 & 0 & 1.33 & 2 & 0 & 0.00 & 0.01 \\
\hline 6 & 2 & 0.57 & 0 & 0 & 0.05 & 0.20 \\
\hline 7 & 0 & 0.06 & 0 & 0 & 0.03 & 0.00 \\
\hline 8 & 2 & 0.21 & 0 & 0 & 0.12 & 0.10 \\
\hline 9 & 0 & 1.8 & 1 & 0.062 & 0.32 & 0.25 \\
\hline 10 & 0 & 1.64 & 2 & 0 & 0.00 & 0.01 \\
\hline 11 & 0 & 0.4 & 2 & 0 & 0.04 & 0.02 \\
\hline 12 & 0 & 2.69 & 0 & 0.262 & 0.00 & 0.02 \\
\hline 13 & 0 & 9.54 & 0 & 0 & 0.00 & 0.01 \\
\hline 14 & 0 & 22.32 & 0 & 0.106 & 0.33 & 0.08 \\
\hline 15 & 0 & 0.36 & 2 & 0 & 0.15 & 0.09 \\
\hline 16 & 0 & 1.21 & 1 & 0 & 0.02 & 0.15 \\
\hline 17 & 0 & 0.43 & 2 & 0 & 0.16 & 0.45 \\
\hline 18 & 4 & 3.53 & 1 & 0.028 & 0.06 & 0.21 \\
\hline 19 & 1 & 0.3 & 0 & 0 & 0.00 & 0.28 \\
\hline 20 & 3 & 0.23 & 2 & 0 & 0.11 & 0.30 \\
\hline 21 & 2 & 0.45 & 3 & 0 & 0.00 & 0.48 \\
\hline 22 & 0 & 0.18 & 1 & 0 & 0.48 & 0.10 \\
\hline 23 & 0 & 1.05 & 3 & 0 & 0.01 & 0.12 \\
\hline 24 & 2 & 1.86 & 3 & 0 & 0.01 & 0.23 \\
\hline 25 & 2 & 0.74 & 0 & 0.008 & 0.00 & 0.57 \\
\hline 26 & 0 & 0.72 & 0 & 0 & 0.01 & 0.06 \\
\hline 27 & 1 & 0.37 & 0 & 0 & 0.04 & 0.09 \\
\hline 28 & 0 & 0.1 & 1 & 0 & 0.00 & 0.40 \\
\hline 29 & 1 & 2.11 & 3 & 0 & 0.04 & 0.12 \\
\hline 30 & 0 & 1.42 & 0 & 0 & 0.02 & 0.05 \\
\hline 31 & 0 & 0.05 & 1 & 0 & 0.04 & 0.53 \\
\hline 32 & 0 & 0.09 & 2 & 0 & 0.10 & 0.33 \\
\hline 33 & 0 & 0.1 & 2 & 0 & 0.26 & 0.08 \\
\hline 34 & 0 & 1.75 & 1 & 0 & 0.01 & 0.15 \\
\hline 35 & 0 & 9.36 & 0 & 0 & 0.19 & 0.42 \\
\hline
\end{tabular}

Terrain: "0"represents flat ground; "1"represents the elevation of 0-0.3 meter; "2"represents the elevation of 0.3-0.6 meter; "3"represents the elevation of 0.6-0.9 meter; "4"represents the elevation of more than 0.9 meter.

Type:"0" represents small roadside parks; "1"represents roadside squares; "2"means small street green; " 3 "means building vestibule green space. 
Table 4. Survey statistics of built environment

\begin{tabular}{|c|c|c|c|c|c|c|c|}
\hline \multirow{2}{*}{$\begin{array}{c}\text { Serial } \\
\text { num- } \\
\text { ber }\end{array}$} & \multicolumn{7}{|c|}{ Built environment } \\
\hline & Exit No. & Residence No. & Commerce No. & $\begin{array}{c}\text { Road network } \\
\text { density, } \mathrm{km} / \mathrm{km}^{2}\end{array}$ & $\begin{array}{c}\text { Medical facility } \\
\text { No. }\end{array}$ & School No. & Office No. \\
\hline 1 & 2 & 8 & 14 & 0.024 & 6 & 7 & 7 \\
\hline 2 & 6 & 6 & 12 & 0.024 & 6 & 8 & 7 \\
\hline 3 & 10 & 7 & 12 & 0.024 & 5 & 8 & 6 \\
\hline 4 & 2 & 8 & 11 & 0.024 & 5 & 8 & 7 \\
\hline 5 & 0 & 10 & 12 & 0.021 & 4 & 7 & 9 \\
\hline 6 & 3 & 12 & 10 & 0.031 & 1 & 5 & 11 \\
\hline 7 & 2 & 9 & 10 & 0.020 & 3 & 5 & 5 \\
\hline 8 & 4 & 10 & 23 & 0.024 & 1 & 8 & 17 \\
\hline 9 & 10 & 8 & 11 & 0.024 & 5 & 8 & 7 \\
\hline 10 & 10 & 11 & 10 & 0.025 & 1 & 7 & 9 \\
\hline 11 & 10 & 8 & 5 & 0.025 & 1 & 2 & 13 \\
\hline 12 & 3 & 8 & 7 & 0.021 & 0 & 3 & 6 \\
\hline 13 & 2 & 3 & 4 & 0.010 & 0 & 1 & 6 \\
\hline 14 & 3 & 2 & 1 & 0.007 & 0 & 1 & 1 \\
\hline 15 & 10 & 15 & 16 & 0.025 & 1 & 5 & 14 \\
\hline 16 & 4 & 17 & 13 & 0.024 & 1 & 2 & 11 \\
\hline 17 & 10 & 14 & 7 & 0.022 & 0 & 1 & 10 \\
\hline 18 & 6 & 15 & 8 & 0.023 & 0 & 1 & 11 \\
\hline 19 & 10 & 7 & 4 & 0.019 & 1 & 3 & 4 \\
\hline 20 & 10 & 8 & 4 & 0.016 & 0 & 1 & 5 \\
\hline 21 & 2 & 8 & 4 & 0.018 & 0 & 1 & 5 \\
\hline 22 & 10 & 4 & 3 & 0.017 & 0 & 4 & 3 \\
\hline 23 & 2 & 13 & 14 & 0.032 & 2 & 7 & 6 \\
\hline 24 & 3 & 12 & 18 & 0.029 & 2 & 4 & 12 \\
\hline 25 & 1 & 12 & 15 & 0.029 & 1 & 4 & 8 \\
\hline 26 & 3 & 15 & 16 & 0.026 & 3 & 7 & 5 \\
\hline 27 & 3 & 13 & 15 & 0.025 & 3 & 7 & 3 \\
\hline 28 & 10 & 11 & 13 & 0.027 & 2 & 7 & 12 \\
\hline 29 & 7 & 12 & 10 & 0.018 & 1 & 2 & 9 \\
\hline 30 & 3 & 16 & 12 & 0.030 & 2 & 4 & 6 \\
\hline 31 & 2 & 9 & 9 & 0.027 & 3 & 3 & 10 \\
\hline 32 & 10 & 9 & 9 & 0.027 & 3 & 3 & 10 \\
\hline 33 & 10 & 9 & 9 & 0.027 & 3 & 3 & 10 \\
\hline 34 & 8 & 12 & 14 & 0.029 & 1 & 6 & 9 \\
\hline 35 & 8 & 5 & 12 & 0.018 & 0 & 5 & 5 \\
\hline
\end{tabular}


Table 5. Data preprocessing of functional facilities

\begin{tabular}{|c|c|c|c|c|c|c|c|c|}
\hline \multirow{3}{*}{$\begin{array}{c}\text { Serial } \\
\text { num- } \\
\text { ber }\end{array}$} & \multicolumn{8}{|c|}{ Functional facilities } \\
\hline & $\mathrm{a}$ & l & $\mathrm{b}$ & l & l & c & $\mathrm{d}$ & $\mathrm{e}$ \\
\hline & Montior No. & Toliet No. & $\begin{array}{l}\text { Lighting } \\
\text { device No. }\end{array}$ & $\begin{array}{l}\text { Water supply } \\
\text { facility No. }\end{array}$ & $\begin{array}{l}\text { Underground } \\
\text { parking lot No. }\end{array}$ & $\begin{array}{c}\text { Fire facility } \\
\text { No. }\end{array}$ & $\begin{array}{c}\text { Identification } \\
\text { plate No. }\end{array}$ & Bench No. \\
\hline 1 & 0 & 1 & 1 & 3 & 0 & 2 & 1 & 1 \\
\hline 2 & 0 & 0 & 3 & 0 & 0 & 0 & 1 & 5 \\
\hline 3 & 2 & 0 & 2 & 5 & 1 & 1 & 4 & 4 \\
\hline 4 & 0 & 0 & 0 & 0 & 0 & 0 & 0 & 2 \\
\hline 5 & 0 & 0 & 0 & 0 & 0 & 0 & 0 & 0 \\
\hline 6 & 0 & 0 & 0 & 0 & 0 & 0 & 0 & 2 \\
\hline 7 & 0 & 0 & 0 & 0 & 0 & 0 & 0 & 0 \\
\hline 8 & 0 & 0 & 0 & 0 & 1 & 0 & 0 & 2 \\
\hline 9 & 1 & 1 & 3 & 5 & 0 & 0 & 0 & 3 \\
\hline 10 & 0 & 0 & 0 & 0 & 0 & 0 & 0 & 4 \\
\hline 11 & 0 & 0 & 0 & 0 & 0 & 0 & 0 & 2 \\
\hline 12 & 0 & 1 & 0 & 0 & 0 & 0 & 0 & 2 \\
\hline 13 & 0 & 0 & 0 & 0 & 0 & 0 & 0 & 0 \\
\hline 14 & 0 & 1 & 2 & 0 & 0 & 0 & 1 & 4 \\
\hline 15 & 0 & 0 & 0 & 0 & 0 & 0 & 0 & 1 \\
\hline 16 & 0 & 0 & 0 & 0 & 0 & 1 & 0 & 0 \\
\hline 17 & 0 & 0 & 0 & 0 & 0 & 0 & 0 & 3 \\
\hline 18 & 3 & 0 & 3 & 2 & 2 & 2 & 3 & 7 \\
\hline 19 & 0 & 0 & 0 & 0 & 0 & 0 & 0 & 6 \\
\hline 20 & 0 & 0 & 0 & 0 & 0 & 0 & 0 & 4 \\
\hline 21 & 0 & 0 & 0 & 0 & 0 & 1 & 0 & 0 \\
\hline 22 & 0 & 0 & 0 & 5 & 1 & 0 & 0 & 0 \\
\hline 23 & 0 & 0 & 0 & 1 & 0 & 0 & 0 & 0 \\
\hline 24 & 1 & 0 & 1 & 0 & 1 & 1 & 2 & 4 \\
\hline 25 & 0 & 0 & 0 & 0 & 0 & 0 & 0 & 0 \\
\hline 26 & 0 & 0 & 0 & 0 & 0 & 0 & 0 & 1 \\
\hline 27 & 0 & 0 & 0 & 1 & 0 & 1 & 1 & 5 \\
\hline 28 & 0 & 1 & 0 & 0 & 0 & 0 & 0 & 4 \\
\hline 29 & 1 & 0 & 1 & 4 & 1 & 0 & 0 & 7 \\
\hline 30 & 0 & 0 & 0 & 0 & 0 & 0 & 0 & 1 \\
\hline 31 & 0 & 0 & 0 & 0 & 0 & 0 & 0 & 5 \\
\hline 32 & 0 & 0 & 0 & 0 & 0 & 0 & 0 & 1 \\
\hline 33 & 0 & 0 & 0 & 0 & 0 & 0 & 0 & 0 \\
\hline 34 & 0 & 0 & 1 & 0 & 0 & 0 & 0 & 7 \\
\hline 35 & 3 & 2 & 3 & 2 & 1 & 2 & 4 & 7 \\
\hline
\end{tabular}

The follows are the ranges of the code in the table. They are determined by the value distribution.

The factor labeled as "/ " use the initial data and do not assign them.

Functional facilities

a. Number of monitors: " 0 " is for $0-3$; " 1 " is for $3-6$; " 2 " is for $7-10$; " 3 " is for more than 10 .

b. Number of lighting devices: " 0 " is for $0-19$; " 1 " is for $20-39$; " 2 " is for $40-59$; " 3 " is for more than 60.

c. Number of fire facilities: " 0 " is for $0-4$; " 1 " is for $5-9$; " 2 " is for more than 10.

d. Number of identification plates: " 0 " is for 0 ; " 1 " is for $1-3$; " 2 " is for $4-6$; " 3 " is for $7-9$; " 4 " is for more than 10 .

e. Number of benches: " 0 " is for $0-9$; “ 1 " is for $10-19$; " 2 " is for $20-29$; “ 3 " is for $30-39$; " 4 " is for $40-49$; " 5 " is for $50-59$; " 6 " is for $60-69$; " 7 " is for more than 70 . 
Table 6. Data preprocessing of spatial form

\begin{tabular}{|c|c|c|c|c|c|c|}
\hline \multirow{3}{*}{$\begin{array}{c}\text { Serial } \\
\text { number }\end{array}$} & \multicolumn{6}{|c|}{ Spatial form } \\
\hline & $\mathrm{f}$ & g & $\mathrm{h}$ & $\mathrm{i}$ & $\mathrm{j}$ & $\mathrm{k}$ \\
\hline & Terrian, $\mathrm{m}$ & Area, $\mathrm{hm}^{2}$ & Type & Water area, $\mathrm{hm}^{2}$ & Lawn area, $\mathrm{m}^{2}$ & Pavement area, $\mathrm{hm}^{2}$ \\
\hline 1 & 4 & 0 & 0 & 1 & 0 & 1 \\
\hline 2 & 4 & 2 & 1 & 0 & 4 & 0 \\
\hline 3 & 0 & 7 & 3 & 3 & 1 & 4 \\
\hline 4 & 4 & 0 & 0 & 0 & 1 & 3 \\
\hline 5 & 0 & 4 & 2 & 0 & 0 & 0 \\
\hline 6 & 2 & 1 & 0 & 0 & 0 & 1 \\
\hline 7 & 0 & 0 & 0 & 0 & 0 & 0 \\
\hline 8 & 2 & 0 & 0 & 0 & 1 & 0 \\
\hline 9 & 0 & 5 & 1 & 4 & 3 & 2 \\
\hline 10 & 0 & 5 & 2 & 0 & 0 & 0 \\
\hline 11 & 0 & 1 & 2 & 0 & 0 & 0 \\
\hline 12 & 0 & 8 & 0 & 5 & 0 & 0 \\
\hline 13 & 0 & 9 & 0 & 0 & 0 & 0 \\
\hline 14 & 0 & 9 & 0 & 5 & 3 & 0 \\
\hline 15 & 0 & 1 & 2 & 0 & 1 & 0 \\
\hline 16 & 0 & 4 & 1 & 0 & 0 & 1 \\
\hline 17 & 0 & 1 & 2 & 0 & 1 & 4 \\
\hline 18 & 4 & 9 & 1 & 2 & 0 & 2 \\
\hline 19 & 1 & 0 & 0 & 0 & 0 & 2 \\
\hline 20 & 3 & 0 & 2 & 0 & 1 & 2 \\
\hline 21 & 2 & 1 & 3 & 0 & 0 & 4 \\
\hline 22 & 0 & 0 & 1 & 0 & 4 & 0 \\
\hline 23 & 0 & 3 & 3 & 0 & 0 & 1 \\
\hline 24 & 2 & 6 & 3 & 0 & 0 & 2 \\
\hline 25 & 2 & 2 & 0 & 1 & 0 & 5 \\
\hline 26 & 0 & 2 & 0 & 0 & 0 & 0 \\
\hline 27 & 1 & 1 & 0 & 0 & 0 & 0 \\
\hline 28 & 0 & 0 & 1 & 0 & 0 & 3 \\
\hline 29 & 1 & 7 & 3 & 0 & 0 & 1 \\
\hline 30 & 0 & 4 & 0 & 0 & 0 & 0 \\
\hline 31 & 0 & 0 & 1 & 0 & 0 & 5 \\
\hline 32 & 0 & 0 & 2 & 0 & 0 & 3 \\
\hline 33 & 0 & 0 & 2 & 0 & 5 & 0 \\
\hline 34 & 0 & 5 & 1 & 0 & 0 & 1 \\
\hline 35 & 0 & 9 & 0 & 0 & 5 & 4 \\
\hline
\end{tabular}

The follows are the ranges of the code in the table. They are determined by the value distribution. The factor labeled as "/" use the initial data and do not assign them.

Spatial form

f. Terrain: " 0 " represents flat ground; "1" represents the elevation of 0-0.3 meter; "2" represents the elevation of $0.3-0.6$ meter; " 3 " represents the elevation of $0.6-0.9$ meter; " 4 " represents the elevation of more than 0.9 meter.

g. Area: “0” represents $0.1-0.3 \mathrm{hm}^{2}$; “ 1 ” represents $0.3-0.6 \mathrm{hm}^{2}$; “2” represents $0.6-0.9 \mathrm{hm}^{2}$; “ 3 " represents $0.9-1.2 \mathrm{hm}$; “ 4 ” represents $1.2-1.5 \mathrm{hm}^{2}$; “5” $\mathrm{m}^{2}$ represents $1.5-1.8 \mathrm{hm}^{2}$; “6”represents $1.8-2.1 \mathrm{hm}^{2}$; “7” represents $2.1-2.4 \mathrm{hm}^{2}$; “8” represents $2.4-2.7 \mathrm{hm}^{2}$; "9" represents more than $2.7 \mathrm{hm}^{2}$.

h. Type: "0" represents small roadside parks; "1" represents roadside squares; "2" means small street green; " 3 ” means building vestibule green space.

i. Water area: " 0 " is for the area of $0 \mathrm{~m}^{2}$; " 1 " is for the area of $0-200 \mathrm{~m}^{2}$; " 2 " is for the area of $200-400 \mathrm{~m}^{2}$; " 3 " is for the area of $400-600$ $\mathrm{m}^{2}$; " 4 " is for the area of $600-800 \mathrm{~m}^{2}$; "5" is for the area of larger than $800 \mathrm{~m}^{2}$. 
j. Lawn area: " 0 " is for the area of $0-0.1 \mathrm{hm}^{2}$; " 1 " is for the area of $0.1-0.2 \mathrm{hm}^{2}$; " 2 " is for the area of $0.2-0.3 \mathrm{hm}^{2}$; " 3 " is for the area of $0.3-0.4 \mathrm{hm}^{2}$; " 4 " is for the area of $0.4-0.5 \mathrm{hm}^{2}$; " 5 " is for the area of larger than $0.5 \mathrm{hm}^{2}$.

k. Pavement area: " 0 " is for the area of $0-0.1 \mathrm{hm}^{2}$; " 1 " is for the area of $0.1-0.2 \mathrm{hm}^{2}$; " 2 " is for the area of $0.2-0.3 \mathrm{hm}^{2}$; " 3 " is for the area of $0.3-0.4 \mathrm{hm}^{2}$; " 4 " is for the area of $0.4-0.5 \mathrm{hm}^{2}$; " 5 " is for the area of $0.5-0.6 \mathrm{hm}^{2}$.

Table 7. Data preprocessing of built environment

\begin{tabular}{|c|c|c|c|c|c|c|c|}
\hline \multirow{3}{*}{$\begin{array}{c}\text { Serial } \\
\text { number }\end{array}$} & \multicolumn{7}{|c|}{ Built environment } \\
\hline & l & 1 & $\mathrm{~m}$ & $\mathrm{n}$ & l & / & o \\
\hline & Exit No. & Residence No. & Commerce No. & $\begin{array}{c}\text { Road network } \\
\text { density, } \mathrm{km} / \mathrm{km}^{2}\end{array}$ & $\begin{array}{c}\text { Medical facility } \\
\text { No. }\end{array}$ & School No. & Office No. \\
\hline 1 & 2 & 2 & 4 & 2 & 6 & 7 & 3 \\
\hline 2 & 6 & 1 & 3 & 2 & 6 & 8 & 3 \\
\hline 3 & 9 & 2 & 3 & 2 & 5 & 8 & 2 \\
\hline 4 & 2 & 2 & 3 & 2 & 5 & 8 & 3 \\
\hline 5 & 9 & 3 & 3 & 2 & 4 & 7 & 4 \\
\hline 6 & 3 & 3 & 3 & 3 & 1 & 5 & 5 \\
\hline 7 & 2 & 2 & 3 & 1 & 3 & 5 & 2 \\
\hline 8 & 4 & 3 & 6 & 2 & 1 & 8 & 7 \\
\hline 9 & 9 & 2 & 3 & 2 & 5 & 8 & 3 \\
\hline 10 & 9 & 3 & 3 & 2 & 1 & 7 & 4 \\
\hline 11 & 9 & 2 & 1 & 2 & 1 & 2 & 6 \\
\hline 12 & 3 & 2 & 2 & 2 & 0 & 3 & 2 \\
\hline 13 & 2 & 0 & 1 & 0 & 0 & 1 & 2 \\
\hline 14 & 3 & 0 & 0 & 0 & 0 & 1 & 0 \\
\hline 15 & 9 & 4 & 5 & 2 & 1 & 5 & 6 \\
\hline 16 & 4 & 5 & 4 & 2 & 1 & 2 & 5 \\
\hline 17 & 9 & 4 & 2 & 2 & 0 & 1 & 4 \\
\hline 18 & 6 & 4 & 2 & 2 & 0 & 1 & 5 \\
\hline 19 & 9 & 2 & 1 & 1 & 1 & 3 & 1 \\
\hline 20 & 9 & 2 & 1 & 1 & 0 & 1 & 2 \\
\hline 21 & 2 & 2 & 1 & 1 & 0 & 1 & 2 \\
\hline 22 & 9 & 1 & 0 & 1 & 0 & 4 & 1 \\
\hline 23 & 2 & 4 & 4 & 3 & 2 & 7 & 2 \\
\hline 24 & 3 & 3 & 5 & 2 & 2 & 4 & 5 \\
\hline 25 & 1 & 3 & 4 & 2 & 1 & 4 & 3 \\
\hline 26 & 3 & 4 & 5 & 2 & 3 & 7 & 2 \\
\hline 27 & 3 & 4 & 4 & 2 & 3 & 7 & 1 \\
\hline 28 & 9 & 3 & 4 & 2 & 2 & 7 & 5 \\
\hline 29 & 7 & 3 & 3 & 1 & 1 & 2 & 4 \\
\hline 30 & 3 & 5 & 3 & 2 & 2 & 4 & 2 \\
\hline 31 & 2 & 2 & 2 & 2 & 3 & 3 & 4 \\
\hline 32 & 9 & 2 & 2 & 2 & 3 & 3 & 4 \\
\hline 33 & 9 & 2 & 2 & 2 & 3 & 3 & 4 \\
\hline 34 & 8 & 3 & 4 & 2 & 1 & 6 & 4 \\
\hline 35 & 8 & 1 & 3 & 1 & 0 & 5 & 2 \\
\hline
\end{tabular}

The follows are the ranges of the code in the table. They are determined by the value distribution.

The factor labeled as " $/$ " use the initial data and do not assign them.

Built environment

1. Residence: " 0 " is for $1-3$; " 1 " is for $4-6$; " 2 " is for $7-9$; " 3 " is for $10-12$; " 4 " is for $13-15$; " 5 " is for $16-18$.

$\mathrm{m}$. Commerce: " 0 " is for $1-3$; " 1 " is for $4-6$; " 2 " is for $7-9$; " 3 " is for $10-12$; " 4 " is for $13-15$; " 5 " is for $16-18$; " 6 " is for more than 18 .

n. Road network density: " 0 " is for $0-2$; " 1 " is for $2-4$; " 3 " is for more than 6 ;

o. Office: "0" is for $1-2$; " 1 " is for $3-4$; " 2 " is for $5-6$; " 3 " is for $7-8$; " 4 " is for $9-10$; “5” is for $11-12$; " 6 " is for $13-14$; " 7 " is for more than 15 . 